Check for updates

Tenterden, UK

Cite this as: BMJ 2021;373:n1489 http://dx.doi.org/10.1136/bmj.n1489 Published: 10 June 2021

\section{Covid-19: AstraZeneca vaccine linked with small risk of ITP, real world data show}

\author{
Jacqui Wise
}

The AstraZeneca covid-19 vaccine is associated with a small increased risk of immune thrombocytopenic purpura (ITP), real world data from Scotland's vaccination programme has shown.

The autoimmune bleeding disorder is characterised by a decrease in the number of platelets, which can cause minor bruising in some patients and excessive bleeding and long term illness in others. The authors of the study, published in Nature Medicine, stress that the condition is treatable and that the benefits of vaccination greatly outweigh the risks. ${ }^{1}$

The study analysed general practice data for 2.53 million people who received first doses of covid-19 vaccines between 8 December 2020 and 14 April 2021. Of these 1.71 million people were vaccinated with the AstraZeneca (ChAdOx1) vaccine and 0.82 million with the Pfizer BioNTech (BNT162b2) vaccine. The analysis compared the incidence of blood clots, unusual bleeding, and ITP in those who had been vaccinated and a matched comparison group.

The researchers estimated there are an additional 1.13 cases per 100 ooo doses of ITP after vaccination with the AstraZeneca vaccine. Patients who had ITP after vaccination compared with those who were unvaccinated tended to be older (median age of 69 years compared with 54 years) and to be more likely to have at least one clinical risk condition and to have been in hospital at the time of the event. There were no deaths linked to ITP in the analysis.

Asiz Sheikh, lead study author and professor of primary care research and development at the University of Edinburgh, told a press briefing: "This is reassuring data and the benefits of the AstraZeneca vaccine greatly outweigh the risks."

The study also found weaker evidence of a small increased risk of other arterial blood clot and bleeding events associated with the AstraZeneca vaccine up to 27 days after vaccination. However, there were insufficient data to conclude if there was an association between ChAdOx1 and cerebral venous sinus thrombosis (CVST). There were 19 total CVST events recorded, of which six were among those previously vaccinated. "We are not seeing enough to adequately power an analysis," said Sheikh. "We can't rule out an association completely, but it is as rare as hen's teeth."

No increased risk of thrombocytopenic, thromboembolic, and haemorrhagic adverse events was seen with the Pfizer BioNTech vaccine.

The increased rate of ITP after the AstraZeneca vaccine is comparable with those of other vaccines against conditions such as hepatitis B, measles, mumps, rubella, and influenza, the researchers say.
The background incidence rate of ITP is 6 to 9 per 100 ooo people, Jim McMenamin, incident director for covid-19 at Public Health Scotland, told the briefing. ITP has also emerged as a complication of covid-19 infection with early epidemiological evidence suggesting a rate of $0.34 \%$ among patients admitted to hospital. McMenamin added, "For most people, ITP is not severe and is manageable with appropriate treatment."

A strength of the study is its large size and the researchers' ability to rapidly access and analyse data from linked national databases. A limitation is that very few people had received second doses at the time of the analysis and few people under the age of 40 were included. The study is ongoing, however, and further data will be published in due course.

Concerns have been raised over the safety of the AstraZeneca vaccine and this has resulted in several countries initially temporarily suspending and then restricting its use in certain age groups. In May the Joint Committee on Vaccination and Immunisation advised that under 40 s should receive an alternative to the AstraZeneca vaccine given the very rare risk of vaccine induced thrombosis and thrombocytopenia.

Simpson CR, Shi T, Vasileiou E, et al. First-dose ChAdOx1 and BNT162b2 COVID-19 vaccines and thrombocytopenic, thromboembolic and hemorrhagic events in Scotland. Nat Med 2021;(June). doi: 10.1038/s41591-021-01408-4.

This article is made freely available for use in accordance with BMJ's website terms and conditions for the duration of the covid-19 pandemic or until otherwise determined by BMJ. You may use, download and print the article for any lawful, non-commercial purpose (including text and data mining) provided that all copyright notices and trade marks are retained. 